This site uses cookies. More info $\boldsymbol{\otimes}$ Close By continuing to browse the site you are agreeing to our use of cookies. Find out more here Close

Views \& Reviews Personal View

\title{
Patients can't trust doctors' advice if we hide our financial connections with drug companies
}

BMJ 2014; 348 doi: http://dx.doi.org/10.1136/bmj.g167 (Published 15 January 2014) Cite this as: BMJ 2014;348:g167

- Article

- Related content

- Article metrics

- Rapid responses

- $\underline{\text { Response }}$

\section{Re: Patients can't trust doctors' advice if we hide our financial connections with drug companies}

The idea that disclosure of financial interests would promote patient trust is extremely attractive. Moreover, patients do have greater trust in doctors who are open about such interests.

But patient trust isn't the real issue here. The real issue is the structural untrustworthiness of health care systems and professionals that have financial conflicts of interest to begin with. In this regard, alas, disclosure of conflicts of interest, however full, genuine and accessible, is of no help at all. The reason is simple: it cannot reveal, not even in theory, which of the conflicting interests actually prevails.

The truth must be said: non-disclosure and disclosure equally render informed consent a legal fiction and respect for the patient's autonomy a farce. Either way, the patient is damned. The drug companies know that. They have been very happy with non-disclosure, but they would continue to smile on the way to the bank even if they and those who are on their payroll were forced to go transparent.

Competing interests: As a medical ethicist employed by a medical school, I am being paid, among other things, to convince my students that disclosure of conflicts of interests really promotes patient autonomy and free choice.

\section{January 2014}

Miran Epstein

Reader in Medical Ethics

Barts and The London School of Medicine and Dentistry, Queen Mary University of London

Centre for Primary Care and Public Health, Barts and The London School of Medicine and Dentistry, 58

Turner St. London E1 2AB

Click to like:

247

ß 